\title{
Educação ambiental: implementação da agenda 21 no Centro Municipal de Educação Infantil Monte Verde em Teresina/PI - (Brasil)
}

\author{
Patrícia Maria Martins Napolis ; Lucimar Rodrigues Vieira Curvo²; Alexander Stein de Luca'; Aguinel \\ Messias de Lima²; Luis Paoli Schiffino Gomez'; Sonia Biaggi Alvez de Alencar²; Gecilene Ferreira ${ }^{3}$ \\ \pnapolis@uol.com.br \\ 1. Universidade Federal do Piauí, Picos - PI $\quad$ 2. Instituto Federal de Mato Grosso, Cuiabá - MT \\ 3. Universidade Federal do Tocantins, Palmas - TO
}

Histórico do Artigo:

Recebido em: 18 de maio de 2017

Aceito em: 12 de janeiro de 2018

Publicado em: 30 de junho de 2018

Resumo: A Educação Ambiental surge no âmbito da sociedade como uma necessidade, devido à gravidade da degradação do meio natural e social. É uma educação garantida por lei para todos os níveis de ensino que oportuniza ao educando acesso a informações e desenvolvimento de uma reflexão crítica acerca da realidade à qual pertence. Desde o surgimento do homem na Terra, vêm se percebendo diversos tipos de impactos ambientais, que estão se multiplicando ao longo do tempo. 0 ser humano demonstra não refletir sobre as consequências de suas ações sobre o meio ambiente. Na Educação Infantil, o Referencial Curricular Nacional para a Educação Infantil orienta os professores a trabalharem de modo a ampliar as experiências das crianças, mostrando os diversos modos de explicar e representar o mundo. Este trabalho teve tem como principal objetivo pesquisar as possibilidades de implantar a Agenda 21 escolar no Centro Municipal de Educação Infantil (CMEI) Monte Verde, procurando desenvolver processo de investigação a respeito das implicações da Agenda 21 escolar nos processos de ensino/aprendizagem, analisar as concepções dos limites e possibilidades da utilização da Agenda 21 escolar no cotidiano da sala de aula pelos profissionais da educação do CMEI Monte Verde e identificar 0 interesse das crianças pela preservação do meio ambiente. A presente pesquisa foi desenvolvida e sistematizada a partir de uma investigação de natureza qualitativa de caráter exploratório e se configura como um Estudo de Campo. Para o seu desenvolvimento foram implementadas estratégias de investigação, como: pesquisa bibliográfica e análises dos mesmos, entrevista semiestruturada e observação participante. Constatamos durante a pesquisa que as crianças possuem um entendimento e percepções acerca das questões de meio ambiente, carregam com elas curiosidades e duvidas que não foram atendidas, além de estarem cientes dos problemas ambientais que ocorrem em sua comunidade. As professoras e a equipe escolar, mostram bastante interesse em ensinar seus alunos sobre meio ambiente e possuem um espaço amplo e adequado para isso, mas não possuem a formação adequada para tal. Palavras-chave: Educação Ambiental. Agenda 2l. Educação Infantil.

\section{Environmental education: implementation of the agenda 21 in the Centro Municipal de Educação Infantil Monte Verde in Teresina/PI - (Brazil)}

\begin{abstract}
Environmental Education appears within the scope of society as a necessity, to the extent of the seriousness of the degradation of the natural and social environment. It is an education guaranteed by law for all levels of education and gives the learner access to information and development of a critical reflection of the reality to which it belongs. From the emergence of man on earth, has been perceiving various types of environmental impacts, coming multiplying over time. The human being demonstrates not to reflect on the consequences of his actions towards the environment. In Child Education, the National Curriculum Framework for Early Childhood Education guides teachers to work to expand children's experiences, showing the different ways of explaining and representing the world. This work had as main objective to investigate the possibilities of implanting a school agenda at the Monte Verde Municipal Infant Education Center (CMEI), seeking to develop a research process regarding the implications of the school agenda 21 in the teaching / learning, analyze the conceptions of the limits and possibilities of using the school agenda 21 in the daily routine of the classroom by the CMEI Monte Verde education professionals and identify the children's interest in preserving the environment. The present research was developed and systematized based on a research of a qualitative nature of exploratory nature, being configured as a Field Study. For its development, research strategies were implemented, such as bibliographic research and analysis of the same, semi-structured interview and participant observation. We found during the research that children have a perception in environmental issues, carry with them curiosities and doubts that have not been answered, and are aware of the environmental problems that occur in their community. The teachers and the school staff, show enough interest in teaching their students about the environment and have a wide and adequate space for the achievement of the same, but do not have adequate training to do so.
\end{abstract}

Keywords: Environmental Educatio, Agenda 21, Early Childhood Education. 


\section{Educación ambiental: implementacion de la agenda 21 en el Centro Municipal de Educação Monte Verde en Teresina/PI - (Brasil)}

Resumen: La Educación Ambiental surge en el ámbito de la sociedad como una necesidad, en la medida de la gravedad de la degradación del medio natural y social. Es una educación garantizada por ley para todos los niveles de enseñanza y oportuniza al educando acceso a informaciones y desarrollo de una reflexión crítica de la realidad a la que pertenece. Desde el surgimiento del hombre en la tierra, se vienen percibiendo diversos tipos de impactos ambientales, que vienen se multiplican a lo largo del tiempo. El ser humano demuestra no reflexionar sobre las consecuencias de sus acciones ante el medio ambiente. En la Educación Infantil el Referencial Curricular Nacional para la Educación Infantil orienta a los profesores a trabajar de modo a ampliar las experiencias de los niños, mostrando los diversos modos de explicar y representar al mundo. Este trabajo tuvo como principal objetivo investigar las posibilidades de implantar agenda 21 escolar en el Centro Municipal de Educación Infantil (CMEI) Monte Verde, buscando desarrollar proceso de investigación acerca de las implicaciones de la agenda 21 escolar en los procesos de enseñanza / el aprendizaje, analizar las concepciones de los límites y posibilidades de la utilización de la agenda 21 escolar en el cotidiano del aula por los profesionales de la educación del CMEI Monte Verde e identificar el interés de los niños por la preservación del medio ambiente. La presente investigación fue desarrollada y sistematizada a partir de una investigación de naturaleza cualitativa de carácter exploratorio, se configura como un Estudio de Campo. Para su desarrollo se implementaron estrategias de investigación, como: investigación bibliográfica y análisis de los mismos, entrevista semiestructurada y la observación participante. En la investigación que los niños tienen un percepcion por las cuestiones de medio ambiente, cargan con ellas curiosidades y dudas que no fueron atendidas, además de estar conscientes de los problemas ambientales que ocurren en su comunidad. Las profesoras y el equipo escolar, muestran bastante el interés en enseñar a sus alumnos sobre medio ambiente y poseen un espacio amplio y adecuado para la realización del mismo, pero no poseen una formación adecuada para ello.

Palabras clave: educación ambiental, Agenda 21, Educación Infantil.

\section{INTRODUÇÃO}

Desde o surgimento do homem na Terra, vêm se percebendo diversos tipos de impactos ambientais que, ao longo do tempo, vêm aumentando sua frequência. A relação entre a degradação e a capacidade de recuperação e regeneração da natureza depende, antes de tudo, do estilo de desenvolvimento, com as mediações da estrutura produtiva, do padrão de consumo e da base tecnológica (PERNA et al., 2014). À medida que a espécie humana foi se desenvolvendo, fazendo descobertas sobre novas tecnologias, ampliando o domínio sobre os elementos e sobre a natureza em geral, tomando conta do conhecimento e se apropriando de todos os recursos sem ter a preocupação de cuidar do ambiente a sua volta e das consequências advindas de seus atos, foram se ampliando em intensidade e extensão os impactos ambientais (ARAUJ0, 2015 p. 42).

Para Dias (1994, p. 140), “os recursos da Terra são suficientes para atender as necessidades de todos os seres vivos do planeta, se forem manejados de forma eficiente e sustentável”. Essa percepção ambiental tem uma conotação que direciona o ambiente para a concepção de recurso para consumo, o que criou o longo e lento processo de construção das formas modernas de comportamento e de valores, provocando significativas mudanças na cultura, com a instauração de novas condutas que foram introjetadas na estrutura psíquica, 
Educação ambiental: implementação da Agenda 21 no Centro Municipal de Educação Infantil Monte Verde em Teresina/PI - (Brasil)

levando, assim, à crença de que o consumo de bens é um meio para se viver mais feliz. (ANIRATO; ROTONDAR0, 2016).

Nesse sentido, tem-se o entendimento de que as questões ambientais devem ser pautadas de ações, discussões e políticas públicas no âmbito Global, Nacional, Regional e Local. Para tanto, fazem-se necessários, ainda, instrumentos que possam dirimir essas estratégias de transformação social e ambiental (BORILE; CALGAR0, 2017). Nesse cenário histórico, surge com proposta inovadora a Educação Ambiental emancipatória e transformadora, seja em uma percepção conservacionista ou preservacionista.

As Diretrizes Curriculares Nacional para a Educação Ambiental (CNE, 2012) fazem referência à educação ambiental da seguinte forma:

[...] Educação Ambiental envolve o entendimento de uma educação cidadã, responsável, critica, participativa, em que cada sujeito aprende com conhecimentos científicos e com o reconhecimento dos saberes tradicionais, possibilitando a tomada de decisão transformadora, a partir do meio ambiente natural ou construído no qual as pessoas se integram. A educação Ambiental avança na construção de uma cidadania responsável voltada para culturas de sustentabilidade socioambiental.

Assim, partindo deste escopo frente à complexidade das questões ambientais, a Educação Ambiental deve ser trabalhada na escola de forma interdisciplinar, podendo proporcionar experiências reais e concretas de intervenção (TRISTÃo; TRISTÃo, 2016).

Já no contexto da Educação Infantil, segundo Brasil (1998), tem-se como Referencial Curricular Nacional para a Educação Infantil (RCNEI) a educação ambiental como eixo denominado de Natureza e Sociedade, o qual reúne temas pertinentes ao mundo natural e social. Mostra que "é importante que as crianças tenham contato com diferentes elementos, fenômenos e acontecimentos do mundo, sejam instigadas por questões significativas para observá-los e explicá-los e tenham acesso a modos variados de compreendê-los e representálos".

Durante a Conferência das Nações Unidas sobre Meio Ambiente e Desenvolvimento Humano, que ocorreu no Rio de Janeiro em 1992, representantes de 170 países discutiram a situação do planeta. Durante a Conferência foi decidido elaborar uma Agenda para o século XXI, contendo ações para garantir um futuro melhor com justiça social, respeitando o ser humano e o meio ambiente (0NU, 2017).

Uma das ações colocadas nessa Agenda, foi que cada cidade fizesse uma Agenda 21 Local, com participação de toda população. Com isso, abriu-se espaço para a elaboração da Agenda 21 Local, do bairro, da comunidade, da vila ou das escolas, sendo que com ela é possível 
planejar, agendar, agir em função dos problemas de sua comunidade, buscando uma vida digna e um futuro melhor.

A educação básica e de qualidade é um direito de todos os cidadãos que está assegurado pela Constituição Federal (CF, 1988) e pelo Estatuto da Criança e do Adolescente (PLANALT0, 1990). A educação deve proporcionar a aquisição de habilidades e conhecimentos, proporcionando um desenvolvimento do (a) aluno (a) preparando-o (a) para os desafios da sociedade, visando condições de liberdade, dignidade, respeito e valorização das diferenças (GOMES, 2012).

Pensando em formar um educando crítico e reflexivo sobre os problemas da sociedade, não podemos dessa forma ignorar os problemas ambientais existentes e que afetam a vida de todos. Sobre a Educação Ambiental, a Lei 9795/99 estabelece as seguintes disposições:

Artigo 10. A educação ambiental será desenvolvida como uma prática educativa integrada, contínua e permanente em todos os níveis e modalidade do ensino normal Artigo 11. A dimensão ambiental deve constar dos currículos de formação de professores, em todos os níveis e em todas as disciplinas.

Parágrafo único. Os professores em atividade devem receber formação complementar em sua área de atuação, com o propósito de atender adequadamente ao cumprimento dos princípios e objetivos da Política Nacional de Educação Ambiental (BRASIL, Lei 9795/99, 27 de abril de 1999).

0 Programa Nacional de Educação Ambiental - PRONEA (2003) tem como eixo orientador assegurar:
no âmbito educativo, a integração equilibrada das múltiplas dimensões da sustentabilidade - ambiental, social, ética, cultural, econômica, espacial e política - ao desenvolvimento do país, resultando em melhor qualidade de vida para toda a população brasileira, por intermédio do envolvimento e participação social na proteção e conservação ambiental e da manutenção dessas condições ao longo prazo.

Nesse mesmo sentido, possui as seguintes diretrizes do Ministério do Meio Ambiente e do Ministério da Educação:

- Transversalidade;

- Fortalecimento do SISNAMA ;

- Fortalecimento dos Sistemas de Ensino;

- Sustentabilidade;

- Descentralização espacial e institucional;

- Participação e controle social.

Ainda segundo o PRONEA (2003), o mesmo representa: 
um constante exercício de Transversalidade, criando espaços de interlocução bilateral e múltipla para internalizar a educação ambiental no conjunto do governo, contribuindo assim para a agenda transversal, que busca o diálogo entre as políticas setoriais ambientais, educativas, econômicas, sociais e de infra-estrutura, de modo a participar das decisões de investimentos desses setores e a monitorar e avaliar, sob a ótica educacional e da sustentabilidade, o impacto de tais políticas.

Portanto, percebe-se que a participação e o controle social permeiam as estratégias e as ações da Educação Ambiental, por intermédio da geração e da disponibilização de informações que permitam a participação social na discussão, formulação, implementação, fiscalização e avaliação das políticas ambientais voltadas à construção de valores culturais comprometidos com a qualidade ambiental e a justiça social; e de apoio à sociedade na busca de um modelo socioeconômico mais sustentável.

Nessa mesma perspectiva de políticas públicas e ações educativas para o exercício da cidadania, Santos (2002) complementou colocando que "a interdisciplinaridade em educação ambiental se revela quando cada profissional faz uma leitura do ambiente de acordo com 0 seu domínio de conhecimento específico, contribuindo para a compreensão e auxílio para outras áreas do tema em questão”.

Segundo Albarado e Medeiros (2015 p. 59):

todo processo educativo é importante por que traz algo novo e quando este processo inicia na vida do ser humano desde o seu nascimento, tem grande probabilidade de contribuir efetivamente ao longo de sua vida. E na Educação Infantil é a fase que o ser humano recebe orientações e acompanhamentos que vão interferir na formação de seu caráter, somado ao acompanhamento da família e complementada pela escola não se tem dúvida que se está formando um cidadão consciente, reflexivo, crítico e solidário, decorrente disso se dar tanta importância ao trabalho do professor que além de incentivar e orientar o educando na construção e reconstrução de seus conhecimentos contribui para criar uma cultura de vida responsável ambientalmente.

Assim, na Educação Infantil, as crianças desenvolvem através do convívio com as outras crianças e com a equipe da escola, a capacidade de agir, observar e explorar tudo ao seu alcance, tornando-se participantes do seu processo de aprendizado e criando autonomia para refletir sobre suas ações e as de outras pessoas.

A educação ambiental em todos os níveis da educação deve ser trabalhada com um planejamento prévio e objetivos claros. Deve buscar atividades desafiadoras e problematizadoras, que desenvolvam a criatividade e 0 ato de observação. 
É interessante que a educação ambiental comece com uma abordagem levando em consideração aquilo que a criança sabe, vivencia e assimila, para que, a partir desse ponto, possam ser desenvolvidas atividades através de experimentos e observação de fenômenos, para que assim a criança desenvolva uma maior curiosidade sobre o meio ambiente e o meio em que vive (LEFF, 2009).

Para corresponder à curiosidade das crianças sobre o meio ambiente e possibilitar uma aprendizagem mais significativa, é fundamental que o professor desenvolva atividades de ação, em que a criança pode manifestar seus interesses e dificuldades (LOUREIR0, 2004).

Professores da Educação Infantil orientam seus trabalhos pedagógicos baseados no Referencial Curricular Nacional para a Educação Infantil (BRASIL, 1998), que divide os conteúdos em duas faixas etárias com base na Lei de Diretrizes e Bases da Educação Nacional que explicita no art. 30, capítulo II, seção II: “A educação infantil será oferecida em: I - creches ou entidades equivalentes para crianças de até três anos de idade; II - pré-escolas, para as crianças de quatro a seis anos".

Segundo Brasil (1998), o Referencial Curricular Nacional para a Educação Infantil (RCNEI) consiste em:

[...] um conjunto de referências e orientações pedagógicas que visam a contribuir com a implantação ou implementação de práticas educativas de qualidade que possam promover e ampliar as condições necessárias para 0 exercício da cidadania das crianças brasileiras. Sua função é contribuir com as políticas e programas de educação infantil, socializando informações, discussões e pesquisas, subsidiando 0 trabalho educativo de técnicos, professores e demais profissionais da educação infantil e apoiando os sistemas de ensino estaduais e municipais. (BRASIL, 1998, p. 13).

O RCNEI não se constitui em um documento de cunho obrigatório, com receitas prontas ou manual de como agir em sala de aula junto com as crianças, pois, como o nome já diz é um referencial. Assim, trata-se de uma orientação, de uma proposta aberta em que se busca uma melhor qualidade de ensino das creches e pré-escolas do Brasil, em que cabe aos professores, juntamente com a equipe pedagógica da escola, discutir os melhores métodos de ensino de acordo com a realidade em que estão inseridos.

Os conteúdos contidos no RCNEI referentes ao eixo Natureza e Sociedade (Quadro 1) estão divididos em cinco temas. São eles: 
Educação ambiental: implementação da Agenda 21 no Centro Municipal de Educação Infantil Monte Verde em Teresina/PI - (Brasil)

Quadro 1 - Conteúdos contidos no RCNEI referentes ao eixo Natureza e Sociedade

\begin{tabular}{|c|c|}
\hline TEMAS & CONTEÚDOS \\
\hline $\begin{array}{l}\text { Organização dos Grupos e } \\
\text { de seu Modo de Ser, } \\
\text { Viver e Trabalhar }\end{array}$ & $\begin{array}{l}\text { - Participação em atividades que envolvam histórias, brincadeiras, } \\
\text { jogos e canções que digam respeito às tradições culturais de sua } \\
\text { comunidade e de outras; } \\
\text { - Conhecimento de modos de ser, viver e trabalhar de alguns } \\
\text { grupos sociais do presente e do passado; } \\
\text { - Identificação de alguns papéis sociais existentes em seus } \\
\text { grupos de convívio, dentro e fora da instituição; } \\
\text { - Valorização do patrimônio cultural do seu grupo social e } \\
\text { interesse por conhecer diferentes formas de expressão cultural. }\end{array}$ \\
\hline $\begin{array}{c}\text { Os Lugares e Suas } \\
\text { Paisagens }\end{array}$ & $\begin{array}{l}\text { - observação da paisagem local (rios, vegetação, construções, } \\
\text { florestas, campos, dunas, açudes, mar, montanhas etc.); } \\
\text { - utilização, com a ajuda dos adultos, de fotos, relatos e outros } \\
\text { registros para a observação de mudanças ocorridas nas } \\
\text { paisagens ao longo do tempo; } \\
\text { - valorização de atitudes de manutenção e preservação dos } \\
\text { espaços coletivos e do meio ambiente. }\end{array}$ \\
\hline $\begin{array}{l}\text { Objetos e Processos de } \\
\text { Transformação }\end{array}$ & $\begin{array}{l}\text { - participação em atividades que envolvam processos de } \\
\text { confecção de objetos; } \\
\text { - reconhecimento de algumas características de objetos } \\
\text { produzidos em diferentes épocas e por diferentes grupos sociais; } \\
\text { - conhecimento de algumas propriedades dos objetos: refletir, } \\
\text { ampliar ou inverter as imagens, produzir, transmitir ou ampliar } \\
\text { sons, propriedades ferromagnéticas etc.; } \\
\text { - cuidados no uso dos objetos do cotidiano, relacionados à } \\
\text { segurança e prevenção de acidentes, e à sua conservação. }\end{array}$ \\
\hline Os Seres Vivos & $\begin{array}{l}\text { - estabelecimento de algumas relações entre diferentes espécies } \\
\text { de seres vivos, suas características e suas necessidades vitais; } \\
\text { - conhecimento dos cuidados básicos de pequenos animais e } \\
\text { vegetais por meio da sua criação e cultivo; } \\
\text { - conhecimento de algumas espécies da fauna e da flora } \\
\text { brasileira e mundial; } \\
\text { - percepção dos cuidados necessários à preservação da vida e } \\
\text { do ambiente; } \\
\text { - valorização da vida nas situações que impliquem cuidados } \\
\text { prestados a animais e plantas; }\end{array}$ \\
\hline $\begin{array}{c}\text { Os Fenômenos da } \\
\text { Natureza }\end{array}$ & $\begin{array}{l}\text { - estabelecimento de relações entre os fenômenos da natureza } \\
\text { de diferentes regiões (relevo, rios, chuvas, secas etc.) e as } \\
\text { formas de vida dos grupos sociais que ali vivem; } \\
\text { - participação em diferentes atividades envolvendo a observação } \\
\text { e a pesquisa sobre a ação de luz, calor, som, força e movimento. }\end{array}$ \\
\hline
\end{tabular}

Fonte: Referencial Curricular Nacional para a Educação Infantil (BRASIL, 1998, p.180) 
Os conteúdos do Referencial sobre Natureza e Sociedade favorecem uma interação com o cotidiano da criança de acordo com a sua idade. Partindo dos conhecimentos prévios da criança, cabe ao professor ampliá-los com novas informações de outras localidades, dando oportunidade de a criança desenvolver seu conhecimento através das novas informações e usando sua imaginação.

0 professor, nessa perspectiva, deve estar preparado para as perguntas e dúvidas que as crianças possam vir a ter, aplicar em sala uma prática reflexiva e estar preparado para lidar com as diferentes opiniões que surjam, além de mediar as relações sociais na sala de aula, evitando qualquer tipo de preconceito e discriminação.

Ainda nas últimas três décadas do século passado, ao serem feitas análises da situação do planeta, ficou evidente uma necessidade urgente de mudança do modo de vida das pessoas. A situação em que encontrava boa parte da população era de miséria e fome. Além disso, a maneira de viver da maioria das pessoas resultava em um grande desrespeito ao meio ambiente e aos recursos naturais (NOQUEIRA-NET0, 1992).

Pensando em meios para um desenvolvimento com compromisso ambiental para a sustentabilidade, durante a Rio-92 foram aprovados três grandes documentos, dentre eles a Agenda 21.

Segundo o Ministério do Meio Ambiente - MMA (2006) a Agenda 21 é:

[...] é um plano de ação para ser adotado global, nacional e localmente por organizações do sistema das Nações Unidas, governos e pela sociedade civil, em todas as áreas em que a ação humana impacta o meio ambiente. Constitui-se na mais abrangente tentativa já realizada de orientar para um novo padrão de desenvolvimento para o século XXI, cujo alicerce é a sinergia da sustentabilidade ambiental, social e econômica, perpassando em todas as suas ações propostas.

A Agenda 21 não é um documento de imposição ou obrigação, trata-se de um documento de princípios e compromisso ético, corresponde a um plano de ações, com objetivos e metas, não focando somente em problemas relacionados aos danos à Natureza, pois tem como foco, também, o desenvolvimento sustentável e a qualidade de vida dos povos de diferentes nações.

Para a elaboração da Agenda 21 é necessário que haja um processo de planejamento participativo, no qual toda a população daquela região é convidada a participar do processo de construção, aplicação e avaliação. Segundo SANTIAG0 e BASTOS (in CADEI, 2010, p.26), entendese o planejamento participativo como "o processo de organização coletiva do trabalho de 
Educação ambiental: implementação da Agenda 21 no Centro Municipal de Educação Infantil Monte Verde em Teresina/PI - (Brasil)

planejar, acompanhar, avaliar e, se for necessário, planejar novas ações com objetivos definidos".

A Agenda 21 é um documento assinado em 14 de junho de 1992, no Rio de Janeiro, por 179 países, resultado da "Conferência das Nações Unidas sobre Meio Ambiente e Desenvolvimento" - Rio 92, podendo ser definida como um "instrumento de planejamento participativo visando o desenvolvimento sustentável”.

Segundo o Ministério do Meio Ambiente - MMA (2017), a Agenda 21 Brasileira é:

\begin{abstract}
um processo e instrumento de planejamento participativo para o desenvolvimento sustentável e que tem como eixo central a sustentabilidade, compatibilizando a conservação ambiental, a justiça social e o crescimento econômico. 0 documento é resultado de uma vasta consulta à população brasileira, sendo construída a partir das diretrizes da Agenda 21 global. Trata-se, portanto, de um instrumento fundamental para a construção da democracia participativa e da cidadania ativa no País.
\end{abstract}

Historicamente, a Agenda 21 teve a sua primeira fase com a construção da Agenda 21 Brasileira. Esse processo que se deu de 1996 a 2002, foi coordenado pela Comissão de Políticas de Desenvolvimento Sustentável e da Agenda 21 Nacional (CPDS) e teve o envolvimento de cerca de 40 mil pessoas de todo o Brasil. 0 documento Agenda 21 Brasileira foi concluído em 2002 (MMA, 2017).

A partir de 2003, a Agenda 21 brasileira entrou na fase de implementação assistida pela CPDS e foi elevada à condição de Programa do Plano Plurianual, (PPA 2004-2007). Agora como programa, ela adquiriu mais força política e institucional, passando a ser instrumento fundamental para a construção do Brasil Sustentável, estando coadunada com as diretrizes da política ambiental do Governo, com a transversalidade, com o desenvolvimento sustentável e com o fortalecimento do SISNAMA, além de ter participação social e adotar referenciais importantes como a Carta da Terra (MMA, 2017).

Portanto, para o Ministério do Meio Ambiente - MMA (2017), a Agenda 21, que tem provado ser um guia eficiente para processos de união da sociedade, compreensão dos conceitos de cidadania e de sua aplicação, é hoje um dos grandes instrumentos de formação de políticas públicas no Brasil.

A partir de 2003, intensificou-se sua implementação, consolidando a ideia que a Agenda 21 tem enorme importância como instrumento popular e propulsor da democracia brasileira, visando a participação e a ação coletiva da sociedade, tendo sido inseridas as suas diretrizes no Plano de Governo Federal e nas orientações estratégicas (MMA, 2017). 
Passou, através de ações governamentais, a ser uma prioridade para orientar e elaborar a implementação de Agendas 21 locais com base nos princípios da Agenda 21 Brasileira, em consonância com a Agenda global. Nesse escopo foi reconhecida a importância do nível local na concretização de políticas públicas sustentáveis (MMA, 2017).

Segundo o Ministério do Meio Ambiente - MMA (2017), os principais desafios do Programa Agenda 21 são:

- Implementar a Agenda 21 Brasileira. Passada a etapa da elaboração, a Agenda 21 Brasileira tem agora o desafio de fazer com que todas as suas diretrizes e ações prioritárias sejam conhecidas, entendidas e transmitidas, entre outros, por meio da atuação da Comissão de Políticas de Desenvolvimento Sustentável e Agenda 21 Brasileira (CPDS);implementação do Sistema da Agenda 21; mecanismos de implementação e monitoramento; integração das políticas públicas; promoção da inclusão das propostas da Agenda 21 Brasileira nos Planos das Agendas 21 Locais.

- Orientar para a elaboração e implementação das Agendas 21 Locais. A Agenda 21 Local é um dos principais instrumentos para se conduzir processos de mobilização, troca de informações, geração de consensos em torno dos problemas e soluções locais e estabelecimento de prioridades para a gestão de desde um estado, município, bacia hidrográfica, unidade de conservação, até um bairro, uma escola. 0 processo deve ser articulado com outros projetos, programas e atividades do governo e sociedade, sendo consolidado, dentre outros, a partir do envolvimento dos agentes regionais e locais; análise, identificação e promoção de instrumentos financeiros; difusão e intercâmbio de experiências; definição de indicadores de desempenho.

- Implementar a formação continuada em Agenda 21. Promover a educação para a sustentabilidade através da disseminação e intercâmbio de informações e experiências por meio de cursos, seminários, workshops e de material didático. Esta ação é fundamental para que os processos de Agendas 21 Locais ganhem um salto de qualidade, através da formulação de bases técnicas e políticas para a sua formação; trabalho conjunto com interlocutores locais; identificação das atividades, necessidades, custos, estratégias de implementação; aplicação de metodologias apropriadas, respeitando o estágio em que a Agenda 21 Local em questão está.

Neste sentido, o presente trabalho tem como principal objetivo pesquisar as possibilidades de implantar a Agenda 21 escolar no Centro Municipal de Educação Infantil (CMEI) Monte Verde. 
Educação ambiental: implementação da Agenda 21 no Centro Municipal de Educação Infantil Monte Verde em Teresina/PI - (Brasil)

\section{MATERIAL E MÉTODOS}

A pesquisa foi desenvolvida na cidade de Teresina, capital do Piaú, localizada no centro norte do estado a $366 \mathrm{~km}$ do litoral, sendo a única capital do nordeste que não se localiza no litoral. A cidade possui 1.391,981 km² e, segundo dados do Instituto Brasileiro de Geografia e Estatística (IBGE), a população em 2015 foi em torno de 844.245 mil pessoas, sendo que apenas 681.055 dessas pessoas são alfabetizadas. 0 clima predominante é tropical semiúmido, com altas temperaturas, conta com duas estações do ano: o período de chuva e 0 período seco (MEDEIROS, 2013).

0 cenário da pesquisa foi o Centro Municipal de Educação Infantil (CMEI) Monte Verde, que está localizado na Rua Amadeus Paulo no bairro Monte Verde também conhecido como Cidade Industrial, Zona Norte de Teresina, estado do Piauí (Brasil). 0 referido CMEI foi criado em 2013 e não há dados disponíveis sobre a população total que reside no bairro.

0 trabalho foi realizado com uma turma do $2^{\circ}$ (segundo) período, com 18 crianças que têm idade entre cinco e seis anos.

Essa pesquisa foi desenvolvida e sistematizada a partir de uma investigação de natureza qualitativa do tipo histórico-estrutural empregando o método dialético (ZAG0, 2013), visto que a mesma não pretende empregar um instrumento estatístico como base no processo de análise do problema, mas sim, analisar os fenômenos à luz do contexto, buscando soluções, descobrindo conhecimento novo e transformando a realidade.

Segundo Triviños (1987, p. 129) "a pesquisa qualitativa de tipo histórico-estrutural, dialética, parte também da descrição que intenta captar não só a aparência do fenômeno como também sua essência”. Busca não só a raiz do problema, mas também compreender e analisar sua existência, suas relações, suas causas e consequências, e assim procura solução para o problema pesquisado.

Aqui nosso objetivo é descrever como ocorre o processo de ensino-aprendizagem e a aquisição da importância da preservação do meio ambiente por meio da Agenda 21 com os sujeitos pesquisados, além de relatar as contribuições desse método para o desenvolvimento da conscientização da importância do meio ambiente. Deste modo, utilizou-se, nesta pesquisa, o caráter descritivo, que de acordo com Gil (2002, p. 42) "tem como objetivo primordial a descrição das características de determinada população ou fenômeno ou o estabelecimento de relações entre variáveis". 
A presente pesquisa se configura como uma pesquisa-ação participante e para o seu desenvolvimento foram implementadas estratégias de investigação, como: levantamento de material bibliográfico e análise do mesmo, entrevista semiestruturada e observação participante.

A pesquisa-ação segundo Thiollent (1985, p. 14) é:

[...] um tipo de pesquisa com base empírica que é concebida e realizada em estreita associação com uma ação ou com a resolução de um problema coletivo e no qual os pesquisadores e participantes representativos da situação ou do problema estão envolvidos de modo cooperativo ou participativo.

Para a coleta de dados da pesquisa foram utilizados dois instrumentos: a observação participante e a entrevista semiestruturada. Nesse caso, é de suma importância a participação do pesquisador no ambiente a ser pesquisado, pois assim será coletado um número maior de dados.

A observação é um instrumento de coleta de dados que permite que o pesquisador chegue mais perto da perspectiva dos sujeitos pesquisados, mas que precisa ser controlada e sistemática, que precisa de um planejamento minucioso para ocorrer a contento. No decorrer da pesquisa fizemos uma observação participante, que é um tipo de estratégia que requer um grande envolvimento do pesquisador na situação estudada e foi utilizada uma câmera fotográfica com a qual fizemos registros dos vários momentos de aprendizagem e das experiências que as crianças tiveram.

A entrevista é uma técnica de coleta de dados muito utilizada, em que se procura obter, de uma parcela da população, informações verbais (TRIVIÑoS (1967, p. 146).

A identidade dos entrevistados deve ser mantida em sigilo e para melhor análise das respostas são criados codinomes para cada um deles. Durante a pesquisa foram entrevistadas a professora titular com codinome Rosa e a professora auxiliar com codinome Margarida, que trabalham com a turma do $2^{\circ}$ período. No decorrer das entrevistas, foi utilizado - para melhor registro de todo o material fornecido - o gravador de voz e, ainda, fez-se uso de diário de pesquisa para registro de acontecimentos que não puderam ser gravados.

\section{RESULTADOS E DISCUSSÃ0}

Seguindo as orientações do Referencial Curricular Nacional para Educação Infantil, percebe-se a importância de levar em consideração todas e quaisquer informações que as 
Educação ambiental: implementação da Agenda 21 no Centro Municipal de Educação Infantil Monte Verde em Teresina/PI - (Brasil)

crianças possuem sobre determinado assunto a ser estudado. A partir do conhecimento que a criança já possui, poderemos ampliar seu conhecimento. Pensando nisso, foi feito um levantamento sobre o significado de meio ambiente na visão das crianças envolvidas. Aplicouse 18 questionários a crianças de 5 a 6 anos de idade, da Educação Básica, Educação Infantil I.

Pergunta: 0 QUE É MEIO AMBIENTE?

Diante das pequenas respostas de cada criança, fizemos um conceito coletivo do que as crianças daquela sala entendem sobre meio ambiente.

Resposta Coletiva: "Meio ambiente são os cachorros, os gatos, as galinhas e todos os animais que vivem no mundo. São também as árvores, as frutas e as flores”.

Meio ambiente para Coimbra (2002, p.32) é:

[...] o conjunto dos elementos físicos, químicos e biológicos e de suas múltiplas relações, ordenados para a perpetuação da vida e organizados em ecossistemas naturais e sociais, constituindo uma realidade complexa e marcada pela ação da espécie humana.

Dessa maneira, percebemos que o conceito de meio ambiente vai além do conceito que as crianças construíram, abrange não só a fauna e a flora, como também o meio em que vivemos e a interação do ser humano com este. Ciente do conhecimento prévio das crianças, podem ser desenvolvidas atividades em sala de aula ou extraclasse, que possibilitem às crianças a reflexão sobre meio ambiente, visando ampliar seu conhecimento e adquirir novos.

Muitas são as concepções que levam às definições de meio ambiente e estas estão relacionadas com a pluralidade cultural, ou seja, são muitas e variadas (SILVEIRA; BALDIN, 2016).

Reigota (2012, p.36) define meio ambiente como "um lugar determinado e/ou percebido onde estão em relação dinâmica e em constante interação os aspectos naturais e sociais".

Para Sauvé (2005), o ambiente também pode ser percebido de outros modos, tais como: natureza (para apreciar, respeitar e preservar); recurso (para gerir e repartir); problema (para prevenir e resolver); sistema (para compreender e decidir melhor); lugar em que se vive (para conhecer e aprimorar); biosfera (onde se vive junto e em longo prazo); projeto comunitário (que deve empenhar-se ativamente). Além dessas representações sobre meio ambiente, outras também podem ser identificadas e caracterizadas: território, onde a relação de identidade com o meio ambiente é particularmente importante; e paisagem, com a interpretação dos contextos locais, destacando sua dinâmica de evolução histórica e seus componentes simbólicos. 
Dando continuidade às atividades desenvolvidas com as crianças, utilizou-se o método consagrado durante a Rio-92, uma dinâmica da árvore da esperança, em que as crianças escreveram em papéis no formato de folha, seus sonhos para o futuro do meio ambiente. A árvore foi feita de material reciclado e ao término de sua escrita, cada criança pendurava sua folha nos galhos da arvore.

A atividade da árvore da esperança nos mostrou a preocupação e o interesse das crianças, mesmo com a pouca idade, com os problemas enfrentados pela comunidade em que moram. 0 desejo de 11 crianças é que no futuro "Não queimem mais as árvores", 5 crianças desejam que “Não matem mais os animais” e 2 crianças "Que não cortem as árvores”.

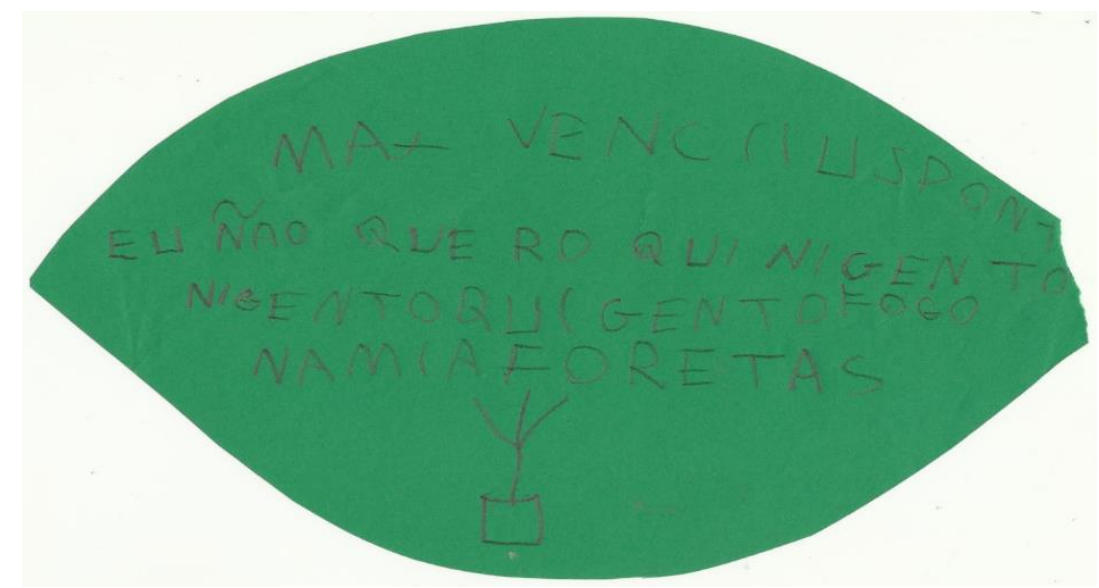

Figura 1: Esperança de Max - "Eu não quero que ninguém toque fogo na minha floresta" Fonte: Centro Municipal de Educação Infantil (CMEI) Monte Verde.

No período em que foram realizadas as pesquisas com as crianças, estavam ocorrendo no bairro Monte Verde e em outros bairros, enormes queimadas. Diversas casas e árvores foram destruídas pelo fogo.

Essa atividade foi de suma importância para estarmos cientes das preocupações das crianças acerca do meio ambiente em que elas vivem e diante do que presenciam.

Percebeu-se, em nossa análise, que as crianças, mesmo que com pouca maturidade e conhecimento de mundo, sem saber das grandes consequências da degradação que os seres humanos trazem ao meio ambiente, sonham com um futuro em que as pessoas não desmatem as florestas e não maltratem os animais. 

Monte Verde em Teresina/PI - (Brasil)

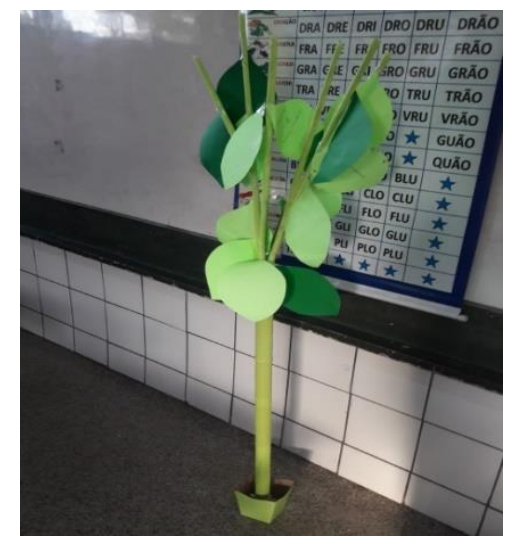

Figura 2: Árvore da Esperança montada pelas crianças.

Fonte: Centro Municipal de Educação Infantil (CMEI) Monte Verde.

A terceira atividade desenvolvida foi o muro das lamentações, onde as crianças criaram em seus tijolos de papel tudo o que elas queriam que tivesse conserto no meio ambiente. A atividade é inspirada no muro das lamentações que fica localizado em Jerusalém, o qual os judeus sempre visitam para rezar e lamentar junto à única parede que restou de um templo.

$\mathrm{Na}$ construção do muro das lamentações das crianças do CMEI Monte verde, percebemos que 12 crianças lamentam os cortes das árvores, 3 crianças não querem os rios sujos e 3 crianças não querem mais que matem os animais.

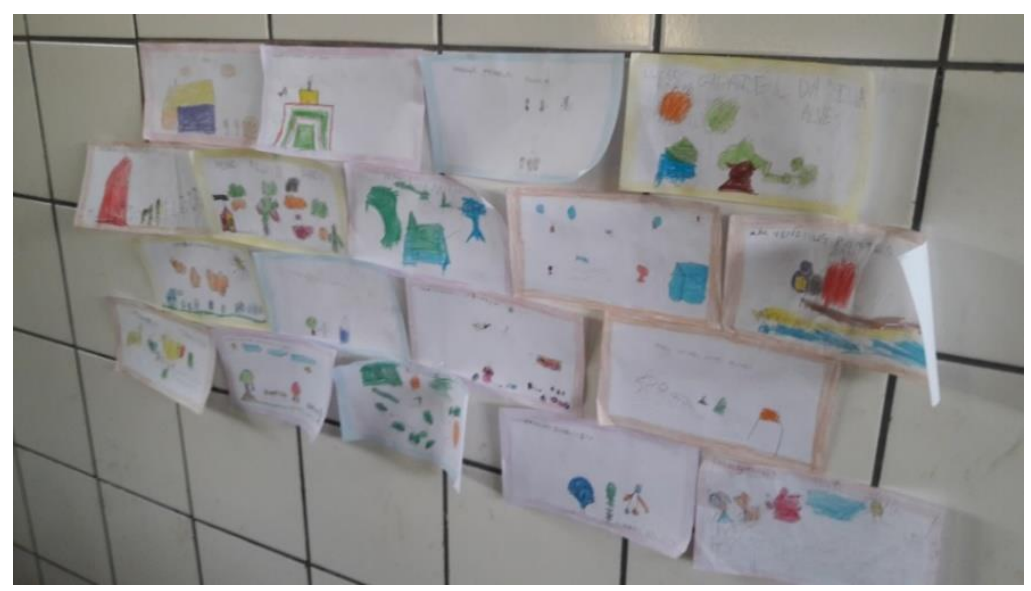

Figura 3: Muro das Lamentações construído pelas crianças. Fonte: Centro Municipal de Educação Infantil (CMEI) Monte Verde.

Ao final das atividades desenvolvidas com as crianças, constatamos que estas têm interesse e curiosidade sobre a fauna e a flora, gostam de perguntar e se preocupam com a degradação que ocorre com a natureza, principalmente na comunidade em que moram.

Um elemento importante para investigação da implantação da Agenda 21 escolar no CMEI Monte Verde é o conhecimento sobre a formação das professoras, suas concepções e 
opiniões sobre educação ambiental e, ainda, se são desenvolvidas atividades de educação ambiental com as crianças.

A primeira entrevistada foi a professora titular, que chamaremos de Rosa. Ela tem Licenciatura em Pedagogia, trabalha há 8 anos com Educação Infantil e, atualmente, dá aulas para crianças de 5 anos. A segunda entrevistada é a professora auxiliar, que chamaremos de Margarida, que ainda está cursando o curso de Licenciatura em Pedagogia e está em sua primeira experiência com sala de aula.

Visando diagnosticar a visão que as professoras têm sobre Educação Ambiental, perguntamos o que elas entendem por EA. Por suas respostas, percebemos que a visão das professoras é de uma educação transformadora da natureza, como se pode ver abaixo:

\footnotetext{
"Educação Ambiental é a forma que temos de ensinar, conscientizar as pessoas a cuidar do nosso meio ambiente. Levar a uma reflexão de como estão agindo com a nossa natureza. Buscando assim uma forma de preservação." (Professora Rosa) "Educação Ambiental é tentar fazer com que as pessoas pensem sobre suas atitudes, que prejudicam a natureza e leva-los a descobrir maneiras de atuarem de forma a preservação do meio ambiente." (Professora Margarida).
}

A palavra transformar nos remete ao pensamento de mudar ou alterar algo. Assim, ao se considerar uma Educação Ambiental como transformadora, pode se perceber a educação enquanto práxis social que contribui no processo de construção de uma sociedade pautada por novos patamares civis e sociais diferentes dos atuais, em que a sustentabilidade da vida e a ética ecológica sejam seu cerne (LOUREIR0, 2002). A concepção de Educação Ambiental transformadora das professoras está relacionada ao ambiente como natureza, à fauna e à flora. Nessa concepção, a educadora trabalha com seus educandos a preservação e respeito com as árvores, animais e rios.

$\mathrm{Na}$ educação infantil são construídos comportamentos e conceitos como os de certo/errado, por isso é que é importante que comece a trabalhar EA desde a Educação Infantil. Sobre isso, Costa (2001, p. 30) acredita que "quanto mais cedo começarmos a trabalhar conceitos e vivências de EA, mais fácil é o processo de interiorização dos mesmos". As professoras relatam, na opinião delas, a importância de trabalhar EA na Educação Infantil:

"É essencial. É um assunto que precisa muito nos dias de hoje ser debatido. E nada melhor de ser iniciado com as nossas crianças, pois eles serão o futuro, então é bom que entendam e reflitam desde cedo a importância do tema." (Professora Rosa) "É muito importante, pois com toda a falta de respeito que as pessoas vêm tendo com o meio ambiente e com todas as catástrofes ambientais, devemos nos posicionar e começar a pensar em mudança. Começar a trabalhar Educação 
Educação ambiental: implementação da Agenda 21 no Centro Municipal de Educação Infantil Monte Verde em Teresina/PI - (Brasil)

Ambiental com as crianças permite que elas interiorizem mais rapidamente a importância da preservação da natureza” (Professora Margarida).

As crianças têm um grande interesse e uma curiosidade enorme no que concerne a animais e à natureza, mas, com o tempo, elas acabam perdendo o interesse e reproduzindo atos dos adultos com quem convivem. É importante que a escola seja um local onde elas possam saciar sua curiosidade e esclarecer suas dúvidas. Nesse ponto, os educadores podem desenvolver atividades lúdicas, de respeito ao meio ambiente, construção de conceitos e reflexão de atitudes para com o meio ambiente. Tais atividades podem ser feitas saindo do ambiente da sala de aula e colocando as crianças em contato direto com a natureza, ou seja, buscando desenvolver atividades que ultrapassem os muros da escola.

Para que ocorra uma Educação Ambiental - EA de qualidade é preciso pensar como está ocorrendo a formação dos professores na EA e se eles têm acesso a cursos ou projetos. Sobre isso as professoras respondem:

\footnotetext{
"Não tenho nenhuma formação na área de educação ambiental. Apesar de achar muito interessante. Ainda não tive a oportunidade." (Professora Rosa)

"Na universidade em que estudo tem uma disciplina chamada Educação Ambiental, que não é obrigatória, mas não cursei, nem participei de nenhum curso e nem de projetos.” (Professora Margarida).
}

Uma boa formação acadêmica e continuada na EA é essencial, pois o que presenciamos atualmente é uma educação ambiental conservadora em algumas escolas, pois os professores, diante da atual realidade ambiental, se veem na responsabilidade de trabalhar Educação Ambiental nas escolas sem uma boa formação na EA. Segundo Guimarães (2004, p. 120), essas práticas "são pouco eficazes, para atuar de forma significativa, no processo de transformação da realidade".

É importante que na grade curricular dos cursos de Magistério e de licenciaturas haja a disciplina Educação Ambiental, em que os futuros professores possam aprender as concepções, a legislação e as metodologias para se trabalhar EA em sala de aula, nas diversas disciplinas.

Devemos destacar que a formação desses futuros educadores da EA, deve ser uma formação que não vise só os métodos de se trabalhar EA, mas que seja uma proposta de formação que rompa com o paradigma conservador e contribua para construção de ambientes educativos de reflexão crítica. Essa educação para Freire (1992 apud Guimarães, 2004, p.129) trata-se da "tentativa de uma educação estimulante do pensar autêntico, que não se deixa 
emaranhar pelas visões parciais da realidade, buscando sempre os nexos que prendem um ponto ao outro, ou um problema a outro”.

Visando analisar em que paradigma se baseia o ensino de EA que ocorre na sala de aula das professoras, perguntamos sobre recursos, procedimentos metodológicos e as atividades de EA desenvolvidas em sala de aula. As respostas que obtivemos foram:

\footnotetext{
"Na escola buscamos desenvolver atividades ligadas à educação ambiental. Gostamos muito da preservação das plantas, até mesmo por que nossa escola tem muitas plantas. Uma área bastante verde. E também trabalhamos com a reciclagem. Produção de brinquedos com esses materiais. Utilizamos o material que temos na escola. E coletamos materiais para a reciclagem." (Professora Rosa).

"Buscamos desenvolver com crianças o respeito e cuidado pelas plantas que temos na escola, além de trabalharmos também a questão de que o lugar de lixo é na lixeira e fazemos alguns brinquedos com materiais recicláveis. Utilizamos as plantas da escola, materiais como garrafas, caixas e tudo que podemos fazer algum brinquedo." (Professora Margarida)
}

Durante as observações, percebemos traços do paradigma conservador, pois as professoras trabalham a reciclagem de materiais, mostrando às crianças como aquele objeto sem utilidade pode se tornar algo útil ou um brinquedo. Mas notamos a carência de uma conversa sobre como aquele material prejudica a natureza e como estão ajudando a preservar a natureza transformando aquele material em algo que possa ser utilizado.

0 espaço da escola tem bastantes árvores e muito verde, e ainda há brinquedos feitos de pneus bem pintados. No decorrer dos dias, foi trabalhado com as crianças as partes da planta, todos saíram da sala para poderem observar as plantas da escola. Durante a atividade, as professoras instigaram as crianças a listarem as semelhanças e diferenças entre as plantas, saciaram a curiosidade das crianças e ampliaram seus conhecimentos.

Por falta de uma formação qualificada em EA, sentimos falta de atividades em que a criança tivesse a oportunidade de cuidar da planta, de tocá-la e de explorar o ambiente natural da escola. Como a escola conta com um ambiente amplo e favorável para plantio, poderia ser desenvolvido plantio de árvores ou uma horta das crianças que seria plantada e cuidada pelas próprias crianças com a ajuda da equipe escolar.

É importante que a EA não ocorra só dentro das escolas, mas que transcenda os muros da educação formal. É preciso que toda a comunidade tenha a possibilidade de conversar e refletir sobre o futuro do meio ambiente. Pensando nisso, questionamos as professoras se a escola desenvolve projetos sobre EA com a comunidade. As professoras relatam que: 
"As escolas juntamente com a comunidade participam de um projeto sobre educação ambiental, onde ocorrem reuniões para se tratar do tema e discutir ações”. (Professora Rosa)

“Já desenvolvemos projetos de conscientização sobre lixo jogado que pode trazer doença para a população" (Professora Margarida).

Os projetos desenvolvidos na escola pesquisada consistem no recolhimento de materiais recicláveis e reuniões que ensinam a reutilizar esses materiais. 0utros projetos são desenvolvidos pela Secretaria Municipal de Educação, como reuniões que ocorrem no ambiente escolar para conscientizar os pais sobre objetos guardados no quintal das casas que servem de criadouro para o mosquito da dengue. Contam também com a participação de dentistas na escola, para ensinar como escovar corretamente os dentes e campanhas de vacinação.

Ao término das entrevistas e das observações, notamos o grande interesse das professoras em desenvolver atividades de EA com as crianças de Educação Infantil. 0 ambiente escolar é propício para a prática de diversas atividades de EA. 0 que falta nesse contexto é uma formação adequada em EA para as professoras começarem a atuar em um paradigma crítico e reflexivo, desenvolvendo atividades com as crianças e com a comunidade.

Após as atividades desenvolvidas com as crianças - a Árvore dos Sonhos e o Muro das Lamentações - tivemos a oportunidade de analisar os dados e diagnosticar os problemas percebidos pelas crianças (Quadro 2).

Quadro 2 - 0s problemas percebidos pelas crianças

\begin{tabular}{|c|l|l|}
\hline Muro das Lamentações & \multicolumn{1}{|c|}{ Árvore dos sonhos } & \multicolumn{1}{c|}{ Tratados para a mudança } \\
\hline $\begin{array}{c}\text { Desmatamento e } \\
\text { Queimadas. }\end{array}$ & “Não queimem mais as árvores” $\begin{array}{l}\text { - Plantar mais árvores; } \\
\text { Fazer campanhas contra desmatamento e } \\
\text { queimadas; } \\
\text { - Confeccionar cartazes de conscientização; } \\
\text { - Plantar horta na escola }\end{array}$ \\
\hline Poluição dos Rios & $\begin{array}{l}\text { - Fazer campanhas de conscientização do lixo } \\
\text { jogado nas ruas; } \\
\text { - Oficinas de Reciclagem; } \\
\text { - Confeccionar cartazes de conscientização. }\end{array}$ \\
\hline Maus tratos aos animais & “Não matem mais os animais” & $\begin{array}{l}\text { Fazer campanhas de respeito e cuidado aos } \\
\text { animais; } \\
\text { - Fazer cartazes e projetos; } \\
\text { - Desenvolver projetos com a comunidade }\end{array}$ \\
\hline
\end{tabular}

Fonte: Centro Municipal de Educação Infantil (CMEI) Monte Verde.

De acordo com o Quadro 2, percebemos que foi possível desenvolver uma Agenda 21 para ser aplicada no CMEI Monte Verde, partindo do conhecimento e da realidade das crianças 
da referida escola. Neste quadro estão contidos os problemas e as esperanças de cada criança e algumas atividades propostas para serem realizados em sala e com a comunidade.

As atividades propostas requerem do professor fugir da sala de aula, transcender os muros da escola e levar a Educação Ambiental para a família, para os amigos e para a comunidade no entorno da escola, objetivando a disseminação do conhecimento, da importância de se preservar o meio ambiente e de ser ensinada e praticada a Educação Ambiental fora da escola. Dentre as atividades, foram propostas a elaboração de projetos e campanhas. Neste ponto é interessante a mobilização de toda a equipe da escola e da comunidade, fazendo propaganda, confeccionando cartazes ou fazendo oficinas.

Com as crianças, é de extrema importância que essas atividades sejam feitas de forma lúdica e concreta, como: plantar árvores ou uma horta; fazer com que as crianças cuidem das plantas diariamente procurando sempre ressaltar a importância destas para nossa sobrevivência, o que fará com que a criança desenvolva o respeito e cuidado pelas plantas; e, ainda, trabalhar reciclagem criando brinquedos e ressaltando o mal que aquele objeto faria para a natureza e o bem que a reciclagem faz, dentre outras atividades.

\section{CONSIDERAÇÕES FINAIS}

A Educação Ambiental (EA) surge no âmbito da sociedade, como um método de emergência visando ajudar a solucionar os problemas de degradação que o homem vem realizando contra o meio ambiente. Através da EA espera-se que educadores trabalhem buscando conscientizar o homem que ele também faz parte da natureza, levando-o a refletir sobre suas ações e as consequências advindas delas.

No ambiente escolar, a EA deve estar presente em todas as matérias, de forma interdisciplinar, além disso, é importante que as atividades desenvolvidas despertem interesse entre os educandos e façam com que estes desenvolvam um pensamento critico e reflexivo, do cenário atual e do futuro do meio ambiente.

Na Educação Infantil é de suma importância, antes de tudo, ter um diagnóstico sobre os conhecimentos prévios das crianças. A partir desse conhecimento, o educador deve trabalhar visando ampliar o nível desse conhecimento. As atividades desenvolvidas com as crianças devem ser planejadas de forma bem lúdica e com experiências concretas, para tornar a aprendizagem mais prazerosa. Entende-se que a Agenda 21 brasileira tem importante papel nas mudanças sociais e ambientais, pois é um processo e um instrumento de planejamento 
Educação ambiental: implementação da Agenda 21 no Centro Municipal de Educação Infantil Monte Verde em Teresina/PI - (Brasil)

participativo para o desenvolvimento sustentável e que tem como eixo central a sustentabilidade, compatibilizando a conservação ambiental, a justiça social e o crescimento econômico. Não distante desse escopo, percebe-se que a Agenda 21 deve partir da escola e esta deve ser a responsável pela educação que influenciará na vida profissional, social e pessoal do (a) aluno (a) e em sua convivência familiar.

Detectou-se também, nesta pesquisa, que foi possível perceber que as crianças possuem um interesse considerável pelas questões de meio ambiente e que carregam com elas curiosidades e dúvidas que ainda não foram atendidas. Além disso, elas estão cientes dos problemas ambientais que acontecem em sua comunidade e se preocupam na medida do possível com o futuro da natureza.

Quanto às professoras do CMEI Monte Verde, estas demonstraram interesse em fazer Educação Ambiental com seus alunos e que, apesar de não terem tido a oportunidade de fazer um curso ou ter uma formação continuada na área, buscam constantemente desenvolver com seus alunos atividades que criem em seus educandos conceitos acerca da importância de preservação e respeito com as plantas e os animais.

A escola possui um ambiente amplo, com muitas árvores e terra. Próximo à escola, existe a horta da comunidade e pode-se ver muitos animais passeando pelas proximidades. Podemos concluir que as crianças estão em contato constante com a natureza, tanto em casa como na escola. Todos esses fatores indicam que há diversas formas diferentes de se trabalhar EA, tanto com as crianças como com as pessoas da comunidade.

Portanto, podemos concluir que a partir da implementação da Agenda 21 no Centro Municipal De Educação Infantil Monte Verde, as crianças desenvolverão uma consciência mais crítica da realidade do meio ambiente. Contudo para que ocorra uma Educação Ambiental de qualidade através da Agenda 21 escolar, é necessário que toda a equipe escolar - não só as professoras - contem com cursos sobre EA, para que haja uma base teórica mais concreta e um melhor desenvolvimento do pensamento crítico e reflexivo com a comunidade.

Acredita-se que a Agenda 21, como um instrumento de construção de saberes e a partir da convivência social local, envolvendo a comunidade, a escola e a família, poderá contribuir para levar os futuros sujeitos sociais, crianças e outras, a uma reflexão permanente sobre as questões ambientais, e nesse contexto, promover e minimizar impactos e transformações ambientais no planeta, com o despertar da sensibilidade e, talvez, da conscientização, a partir do contexto da conservação e preservação da natureza. Assim, acredita-se que teremos dias 
melhores, com mais equidade social, justiça ambiental e que todos possam a ser felizes no convívio em sociedade.

\section{REFERÊNCIAS BIBLIOGRÁFICAS}

ARAÚJ0, S. S. Apropriação dos recursos naturais e conflitos socioambientais no baixo São Francisco em Sergipe e Alagoas. 2016. 359 f. Tese (Pós-Graduação em Desenvolvimento e Meio Ambiente) - Universidade Federal de Sergipe, São Cristóvão, SE, 2015.

BORILE G. 0. CALGAR0, C. Ética do ambiente e Educação Ambiental. 2017. Revista Atlante. Cuadernos de Educación y Desarrollo (septiembre 2017). En línea: http://www.eumed.net/rev/atlante/2017/09/etica-educacaoambiental.html

BRASIL. Ministério da Educação e do Desporto. Referencial curricular nacional para educação infantil. Brasília: MEC/SEF, 1998.

Diretrizes Curriculares Nacionais para a Educação Ambiental. In: Ministério da Educação e do Desporto. Diretrizes Curriculares Nacionais da Educação Básica. Brasília: MEC/SEF/DICEI, 2013.

Secretaria de Educação Fundamental. Referencial curricular nacional para a educação infantil. Ministério da Educação e do Desporto, Secretaria de Educação Fundamental. - Brasília: MEC/SEF, 1998. 3v.: il.

BRASIL. Ministério do Meio Ambiente. Agenda 21 Local. Resultados selecionados. Brasília/DF, 2011.

Agenda 21. 2003. Disponível em: http://www.mma.gov.br/responsabilidade-socioambiental/agenda21. Acesso em: 23 de fevereiro de 2016.

CADEI, M. De S. Educação Ambiental e Agenda 21 Escolar. 2. ed. Rio de Janeiro: Fundação CECIERJ, 2010.

CARVALHO, V. S. Educação ambiental e desenvolvimento comunitário. Rio de Janeiro: Wak, 2002.

COIMBRA, J. de A. A. Como Você Entende o Meio Ambiente? In: . O Outro Lado do Meio Ambiente. Uma Incursão Humanista na Questão Ambiental. Campinas: Millennium, 2002.

CNE - Conselho Nacional de Educação. 2012. Resolução nº 02, de 15 de junho de 2012, que estabelece as Diretrizes Curriculares Nacionais para a Educação Ambiental. Disponível em: http://portal.mec.gov.br/index.php?option=com_ docmanoview=downloadGalias=10988-rcp002-12-pdfócategory_slug=maio-2012-pdföItemid=30192. Acesso em: 23 de abril de 2016.

DIAS, G.F. Educação ambiental. Princípios e práticas. 5. ed. São Paulo: Global, 1994.

GIL, A. C. Como elaborar projetos de pesquisa. 4. ed. São Paulo: Atlas, 2002.

Como elaborar projetos de pesquisa. 4. ed. São Paulo: Atlas, 2008.

GUIMARÃES, M. A Dimensão Ambiental na Educação. 10. ed. Campinas, SP: Papirus, 1995.

A Formação de Educadores Ambientais. 6. ed. Campinas, SP: Papirus, 2004.

G0MES, N. L. Desigualdades e diversidade na educação. Educ. Soc. [online]. 2012, vol.33, n.120 [cited 2017-10-26], pp.687-693. Available from: <http://www.scielo.br/scielo.php?script=sci_arttext\&pid=S010173302012000300002Glng=enonrm=iso >. ISSN 0101-7330. http://dx.doi.org/10.1590/S0101-73302012000300002. 


\section{Educação ambiental: implementação da Agenda 21 no Centro Municipal de Educação Infantil Monte Verde em Teresina/PI - (Brasil)}

IBGE Instituto Brasileiro de Geografia e Estatística. Cidades. Disponível em: 〈http://cod.ibge.gov.br/232GE $>$ Acesso em: 20 jan. 2016.

LEFF, Enrique. Saber ambiental. sustentabilidade, racionalidade, complexidade, poder. Tradução de Lúcia Mathilde Endlich Orth. 7. Ed.-Petrópolis, RJ: Vozes, 2009.

LOUREIR0, C. F. B. Educação Ambiental e movimentos sociais na construção da cidadania ecológica e planetária. In: LOUREIRO, C. F. B.; LAYRARGuES, P. P.; CASTRO, R. S. de. Educação Ambiental. repensando o espaço da cidadania. São Paulo: Cortez, 2002.

LOUREIR0, C. F. B. Trajetória e fundamentos da educação ambiental. São Paulo: Cortez, 2004.

LOUREIR0, C. F. B. Trajetória e Fundamentos Da Educação Ambiental. 2. ed. São Paulo: Cortez, 2006.

MEDEIROS, R. M. Estudo agrometeorológico para o Estado do Piauí. março. p.119. 2013.

MMA Ministério do Meio Ambiente. Brasília/DF. Agenda 21 e Biodiversidade. Disponível em: 〈http://livroaberto.ibict.br/bitstream/1/749/1/Agenda\%2021\%20e\%20biodiversidade.pdf $>$. Acesso em: 20 dez. 2016.

Brasília/DF. 2017. http://www.mma.gov.br/responsabilidade-socioambiental/agenda-21/agenda-21brasileira. Acesso em 25 de outubro de 2017.

NÁPOLIS, P. M .M; ROSSETE, A. N; FIOREnTIN, S; PINTO, C. E. T. Desafio das Águas: Construindo a Agenda 21 do Pedaço. Mato Grosso do Sul: Unemat, 2008.

NOGUEIRA-NETO, P. A erradicação da miséria: um problema ambiental central. Estud. av. [online]. 1992, vol.6, n.15, pp.111-114. ISSN 0103-4014. http://dx.doi.org/10.1590/S0103-40141992000200008.

0NU - Organização das Nações Unidas para 0 Desenvolvimento. 1992. Disponível em: http://www.onu.org.br/rio20/img/2012/01/rio92.pdf. acesso em: 24 de outubro de 2017.

ONU - Organização das Nações Unidas para o Desenvolvimento. 2017. Disponível em: https://nacoesunidas.org/acao/meio-ambiente/. Acesso em: 24 de outubro de 2017.

PERNA, D.; SOARES, A. M. D.; CURV0, R. J. C.; CURVO, L. R. V. Educação ambiental e a química no curso de Técnico em Agricultura do Instituto Federal de Mato Grosso - Campus Cáceres - MT (Brasil), (2014: Revista DELOS: Desarrollo Local Sostenible, n. 21 (octubre 2014). En línea: http://www.eumed.net/rev/delos/2l/quimica.html

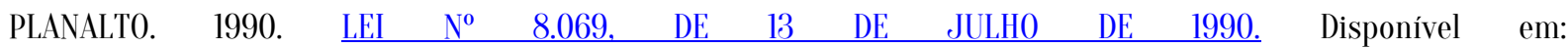
http://www.planalto.gov.br/ccivil_03/leis/L8069.htm. Acesso em: 25 de outubro de 2017.

PREFEITURA MUNICIPAL DE TERESINA - PI. Disponível em: 〈http://www.teresina.pi.gov.br/〉. Acesso em: 20 jan. 2016.

PRONEA - Programa Nacional de Educação Ambiental. 2003. Ministério do Meio Ambiente. Disponível em: www.mma.gov.br/estruturas/educamb/_arquivos/pronea3.pdf. Acesso em: 25 de outubro de 2017.

RAMOS, E. C. Educação Ambiental. Evolução Histórica, Implicações Teóricas e Sociais. Uma Avaliação Crítica. Curitiba: UFPA, 1996. Originalmente apresentada como dissertação de mestrado. Universidade Federal do Paraná.

REIG0TA, M. (2007). Meio Ambiente e Representação Social. 7 ed. São Paulo: Cortez, 87 p.

SAUVÉ, L. Uma cartografia das correntes em educação ambiental. In: SATO, Michèle; CARVALHO, Isabel Cristina de Moura (orgs.). Educação ambiental: pesquisa e desafios. Porto Alegre: Artmed, 2005. p. 11- 44.

SEPLAN Secretaria Municipal de Planejamento e Coordenação. Teresina. Perfil dos Bairros. Disponível em: < http://semplan.teresina.pi.gov.br/>. Acesso em: 20 jan. 2016. 
SilveIRA, M.; S BALDIN, N. Concepções de Meio Ambiente e Educação Ambiental em estudos de percepção ambiental. o caso de professores que lecionam em escolas públicas localizadas em área de bacia hidrográfica. Rev. Eletrônica Mestr. Educ. Ambient. E-ISSN 1517-1256, v. 33, n.1, p. 152-170, jan../abr., 2016.

THIOLLENT, M. Metodologia da pesquisa-ação. 2. ed. São Paulo: Cortez, 1986.

TRISTÃo, V. T. V. TRISTÃo, J. A. M. A contribuição das ONGS para a educação ambiental: uma avaliação da percepção dos stakeholders. Ambient. soc. [online]. 2016, vol.19, n.3 [cited 2017-10-26], pp.47-66. Available from: <http://www.scielo.br/scielo.php?script=sci_arttext\&pid=S1414-753X2016000300047\&lng=en\&nrm=iso $>$. ISSN 1414753X. http://dx.doi.org/10.1590/1809-4422ASOCl32656V1932016.

TRIVIÑoS, A. N. S. Pesquisa Qualitativa. In:____-_. Introdução à pesquisa em Ciências Sociais: A pesquisa qualitativa em educação. São Paulo: Atlas, 1987. cap. 5, p. 116-173

VASCONCELOS, H. S. R. A pesquisa-ação em projetos de Educação Ambiental. In: PERDRINI, A. G. (org). Educação Ambiental. reflexões e práticas contemporâneas. Petrópolis: Vozes, 1997.

ZAG0, L. H. 0 método dialético e a análise do real. Kriterion [online]. 2013, vol.54, n.127 [cited 2017-10-26], pp.109124. Available from: <http://www.scielo.br/scielo.php?script=sci_arttext\&pid=S0100-512X2013000100006 Elng=enơnrm=iso >. ISSN 0100-512X. http://dx.doi.org/10.1590/S0100-512X2013000100006. 